\title{
sciendo
}

Research Article

(C) 2019 Zamiralova et.al.. This is an open access article licensed under the Creative Commons Attribution-NonCommercial-NoDerivs License (http://creativecommons.org/licenses/by-nc-nd/3.0/).

\section{On the Question of Inclusive Education in Higher School: Problems and Prospects}

\author{
Tatyana A. Zamiralova ${ }^{1}$ \\ Konstantin V. Molchanov ${ }^{1}$ \\ Anastasia V. Karpunina ${ }^{2}$ \\ Angelina A. Kvitkovskaya ${ }^{2}$ \\ Anna G. Akhtyan ${ }^{2}$ \\ Natalia A. Bereza ${ }^{2}$ \\ ${ }^{1}$ Omsk State Technical University, Omsk, Russia \\ ${ }^{2}$ Russian State Social University, Moscow, Russia
}

Doi: 10.2478/ajis-2019-0037

\begin{abstract}
The paper studies questions dealing with development of inclusive education in Russia at the current stage. The main approaches to the way inclusion is understood in the present-day post-Soviet space and its particularity as for the higher school are described. The essential and content-related characteristic of this term is discussed in detail. Comparative analysis of various approaches to the understanding of multi-dimensionality of inclusion as a pedagogical phenomenon has been performed. The review of scientific and academic literature by the Russian and foreign researchers who have touched on this range of problems is presented. The main focus areas of development in the process of understanding inclusive education are outlined. Key advantages of implementation of inclusion are systemized. An attempt is made to identify mechanisms that are able to ensure the equality of applicants to the higher-level educational institutions in full. The experience of using inclusive education in Russia is analyzed. With regard to this, main obligations and approaches of the state in relation to applicants and students having disabilities are considered, and conditions, principles and mechanisms of implementation of the current state policy as for the higher professional education are detailed. However, there remains a number of problematic points due to which not all advantages of inclusive education can be made use of to the full extent. The prevailing difficulties and possible ways of resolving them are also noted by the authors.
\end{abstract}

Keywords: inclusive education, inclusion in Russia, social and pedagogic phenomenon, higher school, accessible environment

\section{Introduction}

At the currents stage of social and economic development, the full-on realization has dawned that absolutely each and every individual has a certain set of rights, the right for education included, regardless of their physical, psychological, cultural, ethnic and other particularities. Without sufficient grounds for that, this right cannot be violated or restricted by anyone. In spite of this, in practical life one frequently faces a situation when a certain part of people is subjected to exclusion and thus gets eliminated from the educational process. This is mainly conditioned by the current 
system being unable to satisfy individual needs of such subjects. Meanwhile, it is important to understand that it is not the very learners who cannot study in the system of general education, but it is the system itself not having sufficient means and tools that excludes them automatically. In relation to this, studying the questions of inclusive education that are conditioned by the importance of the existing problems and possible development prospects gains higher relevance. So, this paper is aimed at identifying the problems and prospects of inclusive education in the present-day Russia. The leading approach to studying this problem is theoretical search and explanation of regularities in development of inclusive education. In the paper, the main approaches to interpretation of the notion of inclusive education are detailed, and main opportunities for implementing inclusion are revealed. The materials of the paper are of practical importance for teachers of the higher school and researchers studying inclusion in the higher school.

\section{Literature Review}

It should be emphasized that currently quite a large volume of works by the Russian and foreign scientists of the fields of sociology, psychology and pedagogy are dedicated to questions of inclusive education. The largest contribution has been made by S.V. Alekhina (2015), O.S. Kuzmina (2015), E.N. Kutepova, A.S. Suntsova (2016), O.S. Lopatina (2010), N.G. Sigal (2016), N.V. Skorobogatova (2015), E.V. Shengalts (2015) et al. The analysis of works in inclusive education confirms their controversial nature. When discussing the foreign researchers' experience of the recent years, attention should be paid to works of professor L. Florian of Edinburgh University who performs an extended analysis of the notions of inclusive and special education. This question is quite relevant for the Russian reality and one cannot but agree with conclusions of the author to the effect that the notion of special education has to vanish from the scientific use gradually (Florian, 2019). In their turn, M. Nind and S. Lewthwaite (2017) in their studies of inclusive education express certain concerns as for how complicated the adaptation will be for special needs learners at educational institutions. Meanwhile, it should not be forgotten that some experts maintain the contemporary educational system is not prepared for including the "special" children into the conventional learning. Others remind that co-education is far not a novelty for Russia. In fact, if one turns to history, one can see quite widespread cases of including special needs children into the practice of mass education. Alongside with that, inclusion evokes certain concerns and mistrust with many experts while others, by contrast, feel hope for updating toward humanization and searching for ways to build a socially sought after educational model for the majority of special needs people (Lopatina, 2010). The mentioned facts confirm the relevance of the topic of this research once again.

\section{Research Methodological Framework}

The objective is to identify problems and prospects of inclusive education in the higher school using the example of Russia.

The tasks of the research: characterizing the notion of inclusive education, identifying the main approaches for implementing it within the Russian Federation, finding out some problems of shaping of this phenomenon in Russia.

During this research, scientific literature was analyzed as well as the legislative framework pertaining to inclusive education in Russia. Various approaches to understanding and development prospects of inclusive education in the higher school have been systemized, including a comparative one (Fedotova \& Chigisheva, 2015).

\section{Results and Discussion}

\subsection{Characteristic of the notion "inclusive education"}

With regard to this, first of all the essential and content-related characteristic of the notion of "inclusive education" has to be discussed. The fact is worth paying attention at once that this term 
represents a multi-dimensional notion, which hinders generating a single unified approach to its treatment. So, there is no uniform approach to interpreting the term under analysis both in the Russian and in the foreign literature.

Next, let the existing scientific points of view on the essence and content of definition "inclusive education" be discussed. Generalizing the foreign authors' opinions on this term, N.G. Sigal (2016) suggests that inclusive education be understood as a multi-dimensional pedagogical phenomenon that is intended to ensure productive inclusion and participation of each child in the system of general education, promoting further full-fledged socialization of these children, the fundamental basis of this phenomenon being recognition of uniqueness, value and diversity of all children and exclusion of any forms of their discrimination. The authors of this paper believe the given definition is not completely exhaustive as it refers mainly to the pedagogical staff while overlooking parents, peers studying at one and the same educational institution, and the public in general. This, in its turn, is not quite in line with the concept of inclusive education.

With this borne in mind, it makes sense to perceive inclusive education as a social and pedagogical phenomenon. In particular, O.S. Kuzmina (2015) thinks its main essence can be brought down to building such an educational process in which children having health limitations study together with their healthy peers and receive special pedagogical support and correctional assistance as required which is associated with satisfying the children's special educational needs.

E.V. Shengalts (2015) maintains a similar attitude: inclusive education is the organization of the process of learning in which all children regardless their physical, mental, intellectual, cultural, ethnic, linguistic and other particularities are included into the general system of education and study at one and the same local comprehensive schools which take into account their special educational needs and render any special support required.

Notably, an attempt has been made to consolidate a legal definition of the term under analysis in the Russian Federation. So, in Federal law dated 29/12/2012 No. 273-FL (2012) it is mentioned that inclusive education means ensuring equal access to education for all learners, with the diversity of special educational needs and individual possibilities taken into account. The authors believe such treatment is acceptable as it reflects fundamental points of inclusive education - equal access, consideration of educational needs and individual possibilities.

Moreover, in Methodological guidelines on preparation and organization of vocational guidance for students of inclusive schools having disabilities and health limitations, inclusive education is identified with the including one and represents a system of measures (mechanisms) ensuring execution of the right for education of the disabled children and people having health limitations (Letter of the Ministry of Education and Science of Russia dated 02/02/2016 No. BK163/07 "On directing methodological guidelines", 2016). Fulfillment of this approach allows to the full extent providing the actual, and not formal, equality of the children's rights in getting educational services and equally accessible education for all citizens regardless of their health condition and other subjective characteristics.

Thus, having systemized the presented points of view on the notion of "inclusive education", a grounded conclusion can be made to the effect that the main condition for ensuring it consists in recognizing the value of each person regardless of their individual mental and physical particularities, cognitive, academic and other achievements. With regard to this, it is important to ensure that children would not have to adapt to conditions having formed in a certain educational institution but, on the contrary, it is the system that would adapt to needs and also capacities of particular individuals.

\subsection{Main approaches to the implementation of inclusive education}

In the developed countries, implementation of inclusive education has proven its efficiency and it features certain advantages. In particular, the following can be singled out among the main advantages of the process: special conditions of learning for children having special educational needs are created at the educational institution; flexible adaptive educational environment is created which is completely up to educational needs of all students; learning takes place in conditions of general classes of the mass school, with required psychological and pedagogical 
support rendered to the learners by profile professionals; the learners', students', teachers' and parents' population are prepared for accepting children having health limitations and for creating the comfortable conditions for learning that promote reaching the maximum development level as well as social rehabilitation of the children and their integration into the public; the skills of tolerant attitudes, including tolerance, mercy and mutual respect, are formed in the community.

It should be noted that Russia's inclusive education is at the stage of forming. Alongside with that, by the present point, quite an impressive work on implementing it at preschool institutions, schools and higher education institutions has been completed. So, for example, the Internet portal "Education without borders" was created with support from Moscow City Psychological and Pedagogical University and the Institute of Problems of Inclusive Education (Bulletin of education of Russia. No. 8 (2016). It is targeted at parents bringing up children with health limitations and at professionals of educational institutions. Using the portal, positively everyone who wants can access online the information resource of knowledge for as quickly as practicable resolving particular professional and life situations, obtaining the required information materials and recommendations on questions of organizing the learning of such children in conditions of comprehensive institutions (Gubina et al., 2018).

On top of that, an entire range of laws and regulations are adopted that govern questions of practical application of inclusive education. It is the State program "Accessible environment" covering a complex of problems people having health limitations face (Resolution of the RF Government dated 01/12/2015 No. 1297, 2015) that deserves special attention. Notably, one of the priority focus areas of this program is ensuring the conditions of accessibility for priority objects and services in major fields of the disabled people's life and activity.

Analyzing the content of this document, a conclusion can be made that it is expected to have increased the percentage of comprehensive organizations featuring the multi-purpose barrier-free environment for inclusive education of the disabled children, in the total quantity of comprehensive organizations up to $22,9 \%$ in the Central, North-Western, Southern, Volga Region, up to $23,8 \%$ in the Urals, up to $24,3 \%$ in the Siberian, and up to $23 \%$ in the Far Eastern federal districts by 2020 .

It is remarkable that the RF Government plans to have reached the $100 \%$ target in the indicator of the percentage of disabled children for whom conditions have been created to receive high-quality primary general, main general and secondary general education in the total population of disabled children by 2020 . Naturally, such an aspiration deserves positive evaluation. However, in practice, it is quite challenging to achieve similar results, given the current implementation level of inclusive education.

\subsection{Problems of inclusive education development in Russia}

Still, it has to be borne in mind that there remains an entire set of problems preventing the fullfledged development of inclusive education in Russia. At the same time, it can be spoken about certain difficulties existing at the macro-, meso- and micro-level. In particular, the first group of problems contains the lack of a federal law on special education that would clearly determine the legal framework of the system of inclusive education and economic support for it on the part of the state. Moreover, the priority macro-level support for institutions of correctional and compensating type has been maintained up to the recent time. In its turn, this leads to the fact they remain the most widespread form of teaching the "special" children (Kutepova \& Suntsova, 2016).

Regrettably, the state authorities delegate their powers in the field of implementing the inclusion policy from the state level down to the regional one. This creates further problems, the bulk of which being associated with insufficient material and technical base and financial provision.

At the meso-level, close attention should be paid to the overall "extent" of social intolerance towards people having health limitations; essential resource-related barriers on the way of inclusion at educational institutions, including the lack of material and technical capacities for organizing the "barrier-free environment"; poor inclusive competency of the teaching staff, vague school policy in relation to the inclusive process; rigid orientation of the academic process to achieving the single educational standard by all students without considering their individual particularities and needs; variable nature of programs for gifted children versus the lack of variety of learning programs for 
children having certain deviations.

There remain some problem points at the micro-level, too, in particular, the lack of tolerant attitudes, empathy for children having health limitations, discriminatory attitudes toward them on the part of the people around them; a negative attitude to children having disabilities on the part of healthy students and their parents. Quite an impact is produced by a formal stance on the part of teachers to implementing methods and technologies of individual approach in teaching, the teachers' being unwilling to work in diverse environments, as well as the teachers' obsolete stereotypical attitude to the possibility of co-education of children having no developmental disorders and the "special" students. Certainly, this does not correspond to the policy of inclusive education and deserves a negative evaluation.

S.V. Alekhina (2015) pays attention to such an important point as the lack of medical support of the educational process. Moreover, the inter-agency barriers are evident between the system of education, social protection of the population, and healthcare. The system barriers between correctional and general education institutions are still in place, too.

It has to be understood that children having health limitations, in particular, serious ones, such as autism, Down syndrome etc., face significant difficulties receiving the certificate of completion of the mass school. On top of that, it is quite challenging for such people to receive professional education and, therefore, get employed according to their specialties.

Given the integrated nature of the above problems, they have to be resolved in an integrated way. In the authors' opinion, it makes sense first of all to perceive disability from the standpoint of social model but not medical one. Namely, the former model does not perceive disability as a problem. In this case, it is the very environment that creates barriers for the people. As for the medical model, it is more primitive and it associates disability exclusively with health disorders those with which an ill person becomes a problem for the society, too (Skorobogatova, 2015).

It should be emphasized that orienting to the social approach to disability will allow both the society and educational institutions to eradicate discriminatory negative attitudes toward the "troublesome" children, to overcome the disregard and become much more flexible in carrying out rights and opportunities for all learners to receive similar education.

Much attention has to be paid to forming the inclusive readiness in teaching staff. With regard to this, these transformations touch on both retraining of practicing teachers and the questions of pedagogical higher education institution students' being ready to work in conditions of inclusive education. For this, it is essential for them to master the methods of fulfillment of the individual and competency-based approaches in education, skills of working in diverse environments, adaptive methods and practices of teaching. If training takes place in the distance-learning mode, the fact deserves a positive evaluation. It is necessary for teachers to be able to try their forces in practice and identify any gaps in their own readiness for working in conditions of inclusive education.

\section{Conclusion}

According to the results of the research conducted, the authors could find out what inclusive education is, what opportunities it grants for not only people having health limitations but also for the entire society and the state. According to the authors, the point is the very notion of inclusive education (this being true for the higher school especially), the higher education as such is an inherent human right, and it creates high competitiveness in the labor market and the foundation for a fair society. The experience of applying inclusive education in Russia has been analyzed, proceeding from which an entire set of macro-, meso- and micro-level problems have been found that do not allow making use of all advantages of inclusion to the full extent. Hence, the necessity of creating a clearly organized and efficient infrastructure of specialized support for all those willing to get higher education within the country's educational space, that is, creating opportunities for all the willing ones to freely integrate into the educational space, becomes evident. When forming such a space, it has to be realized quite clearly that the idea of integration consists not in opposing, isolating the mass and the special systems of education but it consists in smoothing out all borders and render them transparent. The fact is also evident that without transforming the daily life consciousness of the public in general as for inclusive education in the higher school, the transition 
to the social model of understanding this range of problems and any change in the professional environment will progress in a very challenging way. It should be noted that currently in the Russian society one can trace a stable trend for understanding inclusive education and its importance for the society. Anyway, steps in this direction have to be taken on and on, because inclusion is a serious move toward humanizing Russia's society in general and its system of education in particular.

\section{References}

Alekhina, S.V. (2015). Condition and development trends of inclusive education in Russia. Development of the Modern Education: Theory, Methodology and Practice, 3(5), 10-15.

Federal law dated 29/12/2012 No. 273-FL (version dated 06/03/2019) "On education in the Russian Federation". Retrieved from http://www.consultant.ru/document/cons_doc_LAW_140174/ on April 20, 2019.

Fedotova O., \& Chigisheva O. (2015). Comparative Analysis: Methodological Optics in the Ideological Context. In: Comparative sciences: interdisciplinary approaches. Series: International perspectives on education and society, 26, 57-81.

Florian, L. (2019). On the necessary co-existence of special and inclusive education. International Journal of Inclusive Education, 1-14.

Gubina, E.V., Komarova, O.N., Rasskazova, A.L., Akhtyan, A.G., \& Bokut, E.L. (2018). Identity features of modern Russian students. Astra Salvensis, 6, 311-320.

Kutepova, E.N., \& Suntsova, A.S. (2016). Theoretical analysis of the problem of inclusive education in the contemporary scientific studies. Bulletin of Cherepovets State University, 2, 105-110.

Kuzmina, O.S. (2015). Training of teachers for working in conditions of inclusion: PhD thesis abstract. Omsk.

Letter of the Ministry of Education and Science of Russia dated 02/02/2016 No. BK-163/07 "On directing methodological guidelines" (alongside with "Methodological guidelines on preparation and organization of vocational guidance for students of inclusive schools having disabilities and HL") (2016). Bulletin of Education of Russia, 8.

Lopatina, V.I. (2010). Inclusive education: broad aspects. Inclusive Education, 1, 12-17.

Nind, M., \& Lewthwaite, S. (2017). Hard to teach: inclusive pedagogy in social science research methods education. International Journal of Inclusive Education, 1-14.

Resolution of the RF Government dated 01/12/2015 No. 1297 (version dated 27/12/2018) "On approval of the state program of the Russian Federation "Accessible environment" for the years of 2011-2020". (2015). Retrieved from http://www.consultant.ru/document/cons_doc_LAW_189921/on April 20, 2019.

Shengalts, E.V. (2015). Inclusive education as the most priority focus area of education for children having health limitations. In: Omsk readings in social sciences and humanities: materials of the International scientific and practical conference (pp. 134-141). Omsk.

Sigal, N.G. (2016). The current state and development trends of the foreign inclusive education: PhD thesis abstract. Kazan.

Skorobogatova, N.V. (2015). Problems of inclusive education at the contemporary stage of establishment of the system of special education. Retrieved from http://shgpi.edu.ru/files/nauka/vestnik/2015/2015-2-36.pdf on April 20, 2019. 